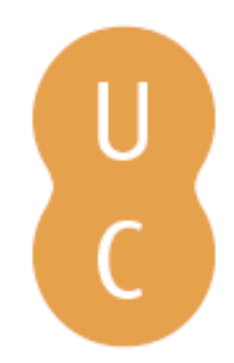

\title{
pompalina
}

\section{La mar: un archivo bien protegido}
Autor(es):
Martin-Bueno, Manuel
Publicado por: Imprensa da Universidade de Coimbra
URL persistente:
URI:http://hdl.handle.net/10316.2/38341
DOI:
DOI:http://dx.doi.org/10.14195/978-989-26-0438-1_1

Accessed : $\quad$ 26-Apr-2023 01:16:08

A navegação consulta e descarregamento dos títulos inseridos nas Bibliotecas Digitais UC Digitalis, UC Pombalina e UC Impactum, pressupõem a aceitação plena e sem reservas dos Termos e Condições de Uso destas Bibliotecas Digitais, disponíveis em https://digitalis.uc.pt/pt-pt/termos.

Conforme exposto nos referidos Termos e Condições de Uso, o descarregamento de títulos de acesso restrito requer uma licença válida de autorização devendo o utilizador aceder ao(s) documento(s) a partir de um endereço de IP da instituição detentora da supramencionada licença.

Ao utilizador é apenas permitido o descarregamento para uso pessoal, pelo que o emprego do(s) título(s) descarregado(s) para outro fim, designadamente comercial, carece de autorização do respetivo autor ou editor da obra.

Na medida em que todas as obras da UC Digitalis se encontram protegidas pelo Código do Direito de Autor e Direitos Conexos e demais legislação aplicável, toda a cópia, parcial ou total, deste documento, nos casos em que é legalmente admitida, deverá conter ou fazer-se acompanhar por este aviso.

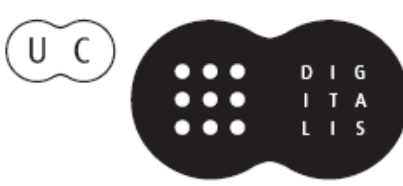


Francisco de Oliveira

Pascal Thiercy

Raquel Vilaça

Coordenação

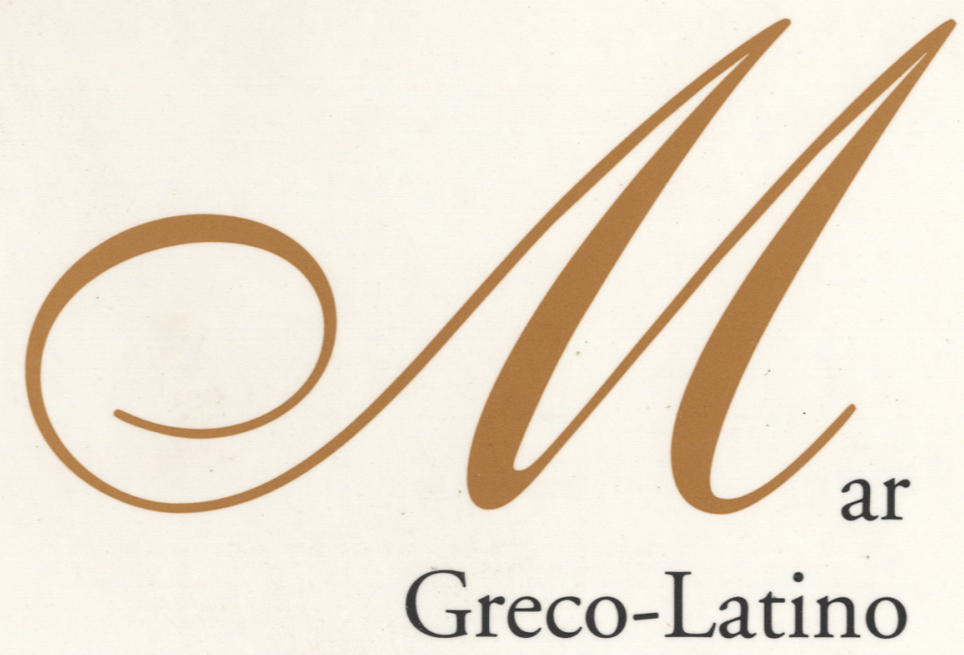

- colmbra 2006 


\title{
LA MAR: UN ARCHIVO BIEN PROTEGIDO(1)
}

\author{
Prof. Manuel MARTIN-BUENO
}

Universidad de Zaragoza

Que los océanos, la mar, son el origen de muchas cosas es cuestión fuera de toda duda y discusión. Que además puede ser uno de los horizontes de futuro para la Humanidad como suministradora de recursos que otrora se creían interminables es también una cuestión hoy casi axiomática. Además y aquí interviene el historiador y arqueólogo, la mar es tal vez el archivo mejor protegido y más extenso con que contamos para examinar nuestro pasado, aprender de él y encarar con mayor seguridad nuestro incierto futuro ${ }^{(2)}$.

A quién es habitante de interior le produce una sana inquietud tratar de sumergirse en temas marinos, tal vez porque nuestra lejanía habitual a la costa produce una permanente sensación de curiosidad por los horizontes abiertos, no por todos sino precisamente por los marinos que esconden mas que enseñan, que permiten un acercamiento muchas veces sosegado pero trasmitiendo siempre esa sensación de respeto que nos aproxima a lo

\footnotetext{
(1) Conferencia pronunciada en éste simposio con motivo de la semana cultural de la Universidad de Coimbra, en el 2006.

(2) Mi mas sincero agradecimiento a la Universidad de Coimbra y en especial al admirado colega y querido amigo el Prof. José d'Encarnação por haber hecho posible mi presencia ante Vds. en esta antigua y venerable Universidad de Coimbra. Gracias sinceras y ruego disculpen mi atrevimiento si les habla de noticias o secretos marinos y oceánicos a quienes son pueblo de navegantes, descubridores y eruditos en temas navales desde los tiempos del Rey D. Enrique el Navegante y la afamada Escuela Naval de Sagres, siendo yo mismo procedente de tierras de interior.
} 
desconocido. Tal vez por ello Aragón, tierra de interior por excelencia, siempre estuvo abierta al mar, el Mediterráneo por vocación histórica y tradición secular ${ }^{(3)}$. Su capital, Zaragoza fue ciudad natal de nuestra infanta compartida y luego reina de Portugal Isabel, Santa Isabel, nacida en el Palacio Real de la Aljafería, prestigioso monumento aragonés y sede de nuestro parlamento regional, a cuyo estudio arqueológico dedicamos una docena de años de nuestra vida investigadora ${ }^{(4)}$.

Pero sigamos con tradiciones y reinas. Hace pocos días, a finales del mes de febrero del 2006, se celebró en un astillero de la costa española, una ceremonia tan antigua como la tradición náutica quiera recordar. La Reina Sofía de España lanzaba a la proa de una nave todavía innominada, la nave oceanográfica Pedro Sarmiento(5), una botella de cava producido en tierras de Aragón, cuya espuma, al romperse la botella en mil pedazos, habría de producir la primera imagen de unas iniciales olas simbólicas que inmedia-

\footnotetext{
${ }^{(3)}$ A título de curiosidad conviene recordar que uno de los primeros manuales de navegación, el primero editado en España lo fue por un aragonés, nacido en los Monearos, tierra seca por excelencia, su autor y título son: Luzón Nogué, J. $\mathrm{M}^{\mathrm{a}}$ : La navigación pré-astronómica en la Antigüedad: utilización de pájaros en la orientación náutica, Lucentum 5 1986 65-86.

(4) Manuel Martín-Bueno. La Aljafería: Investigación Arqueológica. (con R. Erice y P.Sáenz). 183 pags. lams. planos, figs. Zaragoza 1987.

(5) El nombre con el que fue bautizada este nuevo buque oceanográfico, el de un personaje del siglo XVI, Pedro Sarmiento de Gamboa (1532-1592) no puede ser más acertado. Una de las figuras hispanas más sobresalientes de su época. Navegante, cosmógrafo, matemático, soldado, historiador y estudioso de las lenguas clásicas, participó en la expedición de Alvaro de Mendaña que descubrió las Islas Salomón. No obstante su nombre ha quedado unido para siempre al Estrecho de Magallanes, donde viajó en dos ocasiones y fue nombrado gobernador y capitán general de esas tierras. De tales viajes y del desgraciado intento de poblar las regiones australes, donde los infortunados miembros de su expedición quedaron abandonados, muriendo todos antes de que llegaran socorros, se recuerda como gesta terrible. Todavía quedan hoy algunas evidencias de aquel asentamiento que tal vez algún día convenga estudiar y recuperar para documentar arqueológicamente el trágico fin de aquellos desventurados. Muchos datos dudosos en la biografía de Sarmiento de Gamboa, no empañan el valor de su actividad y logros. Se conoce con más detalle su recorrido vital a partir de su nombramiento como capitán de una de las naves de expedición de Mendaña (1567). Llevó a cabo sus viajes al Estrecho de Magallanes en su exploración patagónica en los años 1579-1580, 1581-1586. Fue capturado por corsarios ingleses frente a las Azores cuando volvía a España buscando ayuda para las poblaciones establecidas en el Estrecho y trasladado a Londres. Luego lo sería por los hugonotes franceses en su viaje de regreso a España tras su liberación de las prisiones inglesas, teniendo que pagar rescate tras tres años de cautiverio en Francia hasta 1590. Felipe II le nombra Almirante de la Armada de escolta de las naves del oro y muere en uno de esos barcos frente a Lisboa en 1592.
} 
tamente, convertidas en verdaderas, habrían de abrazar la proa de esa nave sobre las aguas marinas en una transposición poética y rigurosa al mismo tiempo, de costumbres y ritos paganos cuyo origen se pierde en lo oscuro de los tiempos pretéritos.

Si los responsables de asignarle el nombre a este nuevo barco océanográfico conocieran los secretos de las mas remotas tradiciones marineras tal vez debieran haber escogido otro diferente, porque el infortunado personaje, Pedro Sarmiento de Gamboa, murió en la mar, como lo hicieron antes todos sus compañeros olvidados en las gélidas tierras del Estrecho de Magallanes en el siglo XVI, seguramente devorados por las tribus indígenas de Patagonia mientras esperaban un socorro que nunca llegó, de la corte del rey Felipe II y eso es de mal augurio. Pero regresemos al mundo antiguo.

La libación a la efesia Artemisa antes de emprender un viaje por mar, siempre incierto, era una buena medida pero no la única; costumbre que todavía se mantiene en la memoria espontánea de mucha gente de mar cuando se abre una nueva botella de vino o licor a bordo y se vierte un poco de su contenido al agua para aplacar quién sabe que posibles iras de los guardianes de las profundidades que no son pocos en el imaginario popular tradicional como reminiscencia actual de lo que la mitología clásica nos ilustra con largueza. Emprender un viaje por mar era en la Antigüedad algo siempre a considerar con sumo cuidado y en sus preparativos debía excluirse toda precipitación o improvisación, extremo que todavía diferencia con claridad hoy en día un viaje sobre el líquido elemento y otro realizado por cualquier otro medio de comunicación. Cada una de las operaciones, desde la mas simple, incluida la fecha de partida debía estudiarse cuidadosamente y sobre todo asegurarse la protección de aquellas divinidades que pudieran eventualmente facilitar la travesía. Plegarias, sacrificios y ofrendas, eran prácticas imprescindibles si se quería tener éxito en la travesía. Jasón ofrendó un toro a Poseidón (Val.Flac., Argon.,I,188) antes de su partida con los Argonautas para asegurarse una travesía bonancible; pero en caso de peligro 
iniciada la singladura, se podía recurrir al sacrificio de un cordero blanco en la popa para encomendarse a los Dioscuros (Himno Homérico a los Dioscuros, I,11), todo ello sin olvidar la oración formulada por cada individuo a los astros al subir a bordo según leemos en el Satiricón (Petr., Sat., XCIX), traducido todavía en la actualidad por muchos creyentes por la señal de la cruz antes de emprender un viaje al subir a un vehículo, especialmente si se trata de un barco o un avión que se consideran particularmente sujetos a riesgos mayores. Dicha operación debía continuarse mas tarde con un sacrificio colectivo una vez en alta $\operatorname{mar}^{(6)}$. Los ceremoniales propiciatorios existentes en el mundo cristiano recuerdan eficazmente aquellas prácticas. Era también recomendable ofrecer sacrificios a las divinidades de los santuarios costeros visibles durante la travesía, lo que constituía un buen ejercicio de atención ya que la navegación costera de cabotaje permitía numerosos avistamientos. El momento del arribo a destino sin percances también debía ser tenido en cuenta. Nuevamente en el mundo moderno la existencia de numerosos santuarios, a veces pequeñas ermitas o iglesias en pueblos de costa, pregonan una sujeción a prácticas devocionales propiciatorias para obtener beneficios o en agradecimiento de los ya conseguidos en el curso de singladuras a través de mares y océanos ${ }^{(7)}$.

\footnotetext{
${ }^{(6)}$ La circunstancia de realizar dicha ceremonia en alta mar tiene su explicación en las propias características de aquellas navegaciones en las que los peligros estaban al acercarse a tierra o al despegarse de ella. Aprovechar una buena marea siempre fue momento decisivo, lo mismo que franquear una barra litoral si hablamos de estuarios fluviales. El reverso de la moneda lo tenemos también en el hecho de que una vez fuera de la vista de la costa los peligros podían multiplicarse por la falta de puntos de referencia seguros, por los peligros indeterminados que podían sobrevenir y por el propio temor reverencial a esos peligros desconocidos que provocaban ese aferrarse a las costumbres y creencias manteniendo todo el rigor posible en los rituales y ceremonias propiciatorias.

(7) Las costas españolas, especialmente las del norte están especialmente pobladas de pequeños y grandes santuarios erigidos por las poblaciones costeras para procurarse esa protección tan necesaria para aquellos que viven de la mar y que desgraciadamente conviven diariamente con el peligro de no regresar como los pescadores o mariscadores aún en la actualidad con los recursos y medios no solo para la navegación sino para las propias operaciones de rescate.
} 
La tradicional Virgen del Carmen cristiana $^{(8)}$, no significa otro que el recuerdo a las divinidades antiguas, Artemisa, la propia Pallas Atenea; sin olvidar que el propietario indiscutible de los océanos y mares, quién controlaba las fuerzas que los movían o calmaban, quien embridaba a los monstruos que habitaban en sus profundidades, el que gobernaba los vientos y regía los astros que permitían una orientación eficaz, nada menos que el mismo Poseidón, con la colaboración adecuada de divinidades asociadas a estos menesteres como Atenea, Afrodita/Venus y los Dioscuros en su papel de salvadores de navíos. No obstante su fama y eficacia decayó en el periodo helenístico al ser desplazados con ventaja por Isis $^{(9)}$ y Serapis, divinidades alejandrinas que se convirtieron en protectoras indiscutibles de toda la navegación mediterránea. En este contexto la sustitución posterior por la figura de la Virgen, bajo la advocación de la del Carmen, es un buen correlato de la antigua divinidad isíaca.

Esa confianza ciega en la ayuda divina no era otra cosa que un reconocimiento implícito de las dificultades y temores ante una navegación siempre azarosa en un mar, el Mediterráneo, que no por conocido era menos peligroso. Las terribles costas abruptas y llenas de peligros, los vientos, complejos por la propia orografía costera, así como la difícil "ola mediterránea" corta, dura y rápida, era capaz de dar al traste con cualquier avezado navegante y con la estiba mejor calculada.

Pero no queda ahí el elenco de precauciones frente a la mejor y más eficaz vía de intercambio habida en todos tiempos como es la navegación marítima. Las fuentes clásicas son una buena reserva de información y la tradición cristiana tiene en el accidentado viaje de San Pablo del año 60 d.C. entre Cesarea de Palestina y el puerto de Puteoli para arribar a Roma (Hechos

\footnotetext{
(8) La devoción cristiana adjudica la fecha del 15 de Agosto a dicha celebración típicamente marinera con procesiones en las que se traslada la imagen en embarcaciones, normalmente de pesca, engalanadas para la ocasión.

${ }^{(9)}$ El mito de Osiris y todo el trasunto que encierra conviene ser recordado por su relación con las aguas y sus peligros, especialmente con la muerte.
} 
de los Apóstoles, XXVII-XXVIII) un ejemplo conocido. Determinadas fechas estaban vedadas a la navegación, sueños premonitorios, sobre anclas, aguas turbias, llaves, ranas, se consideraban un mal presagio, lo mismo que realizar algunas prácticas como cortarse las uñas o el pelo a bordo, que solamente podía estar justificado en caso de peligro inminente precisamente como ofrenda a los dioses. Alterar esta costumbre provocó que en una travesía dos personajes del Satiricón, Eumolpo y Gitón (Petr., Sat., CIII-CV) fueran sorprendidos por otro pasajero en la nave Isis rapándose la cabeza por la noche y denunciados inmediatamente al capitán quién los castigó a recibir cuarenta azotes "para aplacar a la divinidad tutelar de la nave", ante conducta tan irresponsable e impía. Igualmente estaba prohibido tener relaciones sexuales para que los barcos pudieran mantenerse puros en cuestiones relacionadas con Afrodita, de ahí la tradicional ausencia de mujeres a bordo consideradas poco beneficiosas y como causantes de problemas. El hecho de la permanente inseguridad a bordo no facilitaba precisamente las cuestiones amorosas aunque la cinematografía recreando las relaciones entre Antonio y Cleopatra se empeña en mostrar lo contrario, aunque quién sabe, Actium es evidente que no fue favorable a la enamorada pareja ${ }^{(10)}$.

Morir a bordo era el colmo de las desdichas, no sólo para el protagonista y presagio de nada bueno para nave, un cuerpo no debía conservarse a bordo sino arrojarlo lo antes posible a la mar, costumbre que se ha mantenido escrupulosamente a lo largo de la historia, revestida de razones sanitarias, hasta casi la actualidad. Aún hoy en día en términos de protección del

\footnotetext{
(10) Es obvio que el encuentro entre las flotas de Antonio y Cleopatra por un bando y las naves de Augusto comandadas por Agripa por el otro, no fue un modelo de estrategia por parte de la famosa pareja. Tampoco las maniobras que parece se llevaron a cabo destacaron por su genialidad pero el caso es que el prematuro abandono del campo por la reina egipcia y el desafortunado comportamiento de Marco Antonio abandonando a sus fuerzas hicieron el resto. Tampoco hay evidencia por otra parte de trabajo conjunto de preparación para la batalla por parte de las naves de la flota combinada de la pareja, por lo que las erróneas decisiones tomadas no deben extrañar.
} 
Patrimonio Cultural Sumergido los barcos de guerra hundidos en combate se consideran panteones nacionales por respeto a los que reposan alli ${ }^{(11)}$.

Otros numerosos argumentos utilizados en cuestiones relacionadas con la mar nos dan prueba constante de la infinidad de datos que encierra. Este archivo providencial es menos mudo de lo que a simple vista parece pero para obtener sus respuestas hay que ser cuidadoso con las preguntas. La falta de medios para hacer frente a una niebla traicionera, frecuente en las navegaciones mediterráneas, se intentaba resolver con la colocación de unos ojos pintados en la proa, uno a cada lado, que vieran en la oscuridad mas allá de donde alcanzaba la percepción del ojo humano. En la actualidad el radar y mucho antes la sonda, han resuelto de forma práctica el problema, pero la fuerza de la costumbre está tan arraigada en algunos lugares como en algunos puertos pesqueros italianos del Tirreno, en la Campania, que junto al moderno radar frecuentemente continúan pintando ojos y no es inusual comprobar como en el mástil, junto a las modernas antenas de radio y el mismo radar, se fijan un par de cuernos de toro, que nos hacen recordar directamente al sacrificado por Jasón a Poseidón antes de su famoso viaje en pos del Vellocino de Oro. ${ }^{(12)}$

\footnotetext{
(11) Artículo 1, párrafo 8; artículo 13 relativo a la inmunidad soberana de las naves de estado e incluso la norma 5 del Anexo, de la Convención para la Protección del Patrimonio Cultural Subacuático de la UNESCO, Paris, diciembre 2001. A este respecto esa tradición mantenida en las naves de las armadas de los diferentes países fue fruto de controversia en la mencionada Convención ya que desde el punto de vista de los arqueólogos igual respeto debe tenerse con los restos de náufragos que reposen en barcos hundidos, con independencia de su condición, extremo éste que se agudiza al haberse descubierto ya algún barco negrero con su macabro cargamento abordo. España es también sensible a estos argumentos sobre todo desde el descubrimiento en aguas del Río de la Plata, en la bahía de Maldonado Punta del Este, del navío Asunción que en el siglo XVIII naufragó, pereciendo todo el Regimiento de Albuera. Hace unos años, en la década de los noventa, unos buceadores descubrieron, tras haberlo dejado a la vista tras un temporal, los restos del infortunado navío, con la sorpresa de quedar visibles restos humanos todavía con parte de los uniformes, calzado, etc. La queja de las autoridades españolas y el complejo mundo de autorizaciones y competencias en la materia del patrimonio cultural sumergido en Uruguay ha hecho que el tema permanezca bajo control oficial, pero la recuperación incontrolada de algunos restos se ha producido.

${ }^{12}$ Interrogados algunos patrones de estas embarcaciones al respecto de práctica tan singular no nos dieron más explicación que la tradición familiar o del lugar para seguir haciendo lo que ellos conocían se realizaba desde tiempo inmemorial. Quién sabe si estamos ante el recuerdo, seguramente es así, de las proas con mascarones con protomos de animales, como los toros de
} 
Los ojos pintados ven en la oscuridad, lo mismo que los grandes ojos de la lechuza de Atenea (Atenea Noctiluca, la que ve en la noche), animal nocturno por excelencia y compañero inseparable de la imagen de la diosa, patrona de la navegación y símbolo protector de una de las mas importantes potencias marítimas de la antigüedad clásica. El ojo pintado de Isis, que aparece en muchos casos es referencia inseparable de la divinidad alejandrina y el uso de su nombre para denominar a algunos barcos famosos en el mundo antiguo, garantía de seguridad.

La presencia de animales marinos benéficos como los delfines, que acompañan los tipos de numerosas monedas mediterráneas, singularmente de la potencia siciliana Siracusa es una manera de recordar y reverenciar de manera gráfica a aquellos simpáticos e inteligentes mamíferos marinos que son capaces de guiar a los navegantes acompañando a los barcos en sus singladuras para evitarles los peligros ${ }^{(13)}$.

La mar como dominio de la impunidad es también un topos en la referencias a estos temas. El hombre en el momento en que se aleja de la costa y pierde contacto visual con ella, entra en un mundo peligroso, un paraje en el que le puede acaecer cualquier cosa, no sólo son las fuerzas naturales las encargadas de ofrecer un peligro latente, sino también la concurrencia de otros barcos, de otros hombres, fuera del lugar sujeto a leyes y normas constituido por la tierra firme, la costa. Durante siglos salir a alta mar, perder de vista la costa era entrar en un mundo de inseguridad donde

Costig de Baleares conservados en el Museo de Mallorca o las figuritas de los bronces sardos por ejemplo, todos ellos en el contexto del Mediterráneo occidental en que se dan estas tradiciones citadas.

(13) Sin duda hay que considerar en este contexto la presencia de dichas figuraciones, especialmente cuidadas en las bellísimas monedas siracusanas cuyos cuños fueron obra de famosos artistas como: Eumenos, Sossion, Evainetos, Euthymos, Eukleidas y Phrigyllos. La referencia expresada por algunos autores a la producción o comercio con pescado, caso de las representaciones de atunes en las monedas antiguas de la costa peninsular (Sexi, Abdera. Malaca, etc.), nada tiene que ver con los delfines, mamíferos marinos protegidos reverencialménte desde la Antigüedad por considerarse benéficos en extremo y compañeros de los hombres, a los que precisamente ayudaban sirviéndoles de guía en su navegación. Navegaciones en las que cifraron buena parte de su desarrollo económico los siracusanos y otros ciudadanos del mare nostrum. 
acechaban todos los peligros, donde no había ley a la que acogerse. De donde provenían todos los peligros imaginables. De hecho es habitual en el Mediterráneo encontrar muchas ciudades no precisamente a la orilla del mar, sino en el interior, en los periodos de inseguridad, ya que la costa estaba sujeta a frecuentes razzias e incursiones de piratas e invasores ${ }^{(14)}$.

Por otra parte el temor reverencial que siempre ha supuesto la fuerza generadora y destructora a un tiempo de la mar queda reflejada de manera magistral por las palabras de la poetisa gallega Rosalía de Castro cuando escribía: “...El embravecido mar de Finisterre lanzaba sus verdes y espumosas olas contra los peñascos........ Un sol de invierno, claro pero frío, ilumina aquellas montañas, que ya graníticas, ya arenosas, tienen siempre ese aspecto desolado y salvaje de las comarcas estériles, en cuya tierra no brotan jamás ni arbustos ni verdura, y un silencio lleno de sordos y misteriosos rumores se extendia donde quisiera alcanzar el oído....

Alli no se escucha mas que el silbido del viento y de unas olas siempre en lucha y que amenazan tragar los pequeños pueblecillos que se extienden a la orilla como abandonados despojos de quién nadie se cuida".(15)

Mar adentro, la propia inmensidad, la sensación de inseguridad, el aislamiento y la imposibilidad de comunicarse implicaba la dificultad de recibir ayuda ante cualquier eventualidad que se produjera. La piratería, seguramente tan antigua como la humanidad era peligrosa por la inseguridad que suponía, mas que por las dificultades o trastornos económicos o humanos que pudiera provocar. El mismo hecho de producirse en la mar tenía algo de bastardo, algo que se dejaba al margen, que se escondía porque no se podía controlar. En la misma Roma el servicio de armas en la flota estaba menos considerado que en las legiones, la inseguridad propiciaba la

\footnotetext{
(14) Basta recorrer muchos emplazamientos costeros a lo largo de su costa para verificar este extremo, singularmente las islas mediterráneas son un ejemplo claro como Cerdeña, Malta, etc. (15) Rosalía de Castro, La bija del Mar, Vigo 1859.
} 
desconfianza e inducía a ese relativo desprecio ${ }^{(16)}$. Finalmente las campañas pompeyanas $^{(17)}$ para eliminar a los piratas del Adriático dieron un cierto protagonismo a una lacra que a la par que molesta había supuesto poco prestigio a quiernes la habían combatido.

La historia recoge abundantes episodios que corroboran esa sensación de peligro e impunidad, de hechos detestables, de engaños y subterfugios asociados al escenario marino. Desde la antigüedad hasta el presente la navegación con fines militares por ejemplo, amén del simple transporte de tropas, la guerra en la mar, ha sido el teatro en el que se han permitido toda suerte de alteraciones de la norma establecida. La caballerosidad exigible hasta cierto punto en un enfrentamiento en tierra, desde los combates singulares de los poemas homéricos, a las grandes batallas terrestres del siglo XIX, pasando por las justas medievales, nunca se ha aplicado en la mar. Allí todo ha sido utilizado con ventaja, el engaño, el camuflaje, la embarcación trampa, el corsario, hasta el propio submarino es una versión técnica moderna de la falta de escrúpulos que puede aplicarse en un teatro de operaciones no terrestre. Alejandro utiliza buceadores para atravesar ríos y acercarse a algunas ciudades sin ser vistos por sus defensores, a modo de unos primitivos y arriesgados "comandos marinos", verdaderos antecesores de los "seal" de los marines USA. Ya los asirios habían utilizado odres llenos de aire para facilitar la respiración bajo el agua y también para construir plataformas flotantes para ríos de poco y medio calado, conocido por la iconografía relivaria ${ }^{(18)}$.

\footnotetext{
(10) El asunto ya se viene tratando desde obras clásicas como las de: Casson, L., Ships and Seamanship in the Ancient World, Princeton, 1971, cap. VII; Rougé, J. La Marine dans l'Antiquité, Paris 1975, caps. IX y X, sobre todo; más recientemente Reddé, M. en Mare Nostrum vuelve a recuperar el tema con mayor amplitud.

(17) En el 67 a.C. Cneo Pompeyo Magno resolvió el problema de la piratería y adquirió un prestigio militar suplementario por su acción.

${ }^{(18)}$ Una buena representación de balsa o almadía construida con pellejos inflados en Casson, op. cit, p.370, lam.I.
} 
Uno de los episodios mas famosos, paradigmático en la historia de todos los tiempos, la Guerra de Troya, tiene unas connotaciones navales y marinas muy claras, incluyendo el famoso caballo, símbolo por excelencia del engaño, del que la frase virgiliana (no os fiéis troyanos de los griegos incluso en sus ofrendas) (En., II, v. 48-49). Desde el siglo VIII a.C. en que se debió recoger el poema homérico hasta el presente, el Caballo de Troya es la imagen del peligro sustancial, desde la epopeya homérica al mundo de la informática, la historia continúa.

Pero el Caballo de Troya pensamos hoy con buena carga de razón que fue realmente una nave cuya proa estaba decorada con una cabeza de caballo, animal totémico por excelencia para simbolizar con su rapidez ese cabalgar sobre las olas, crines de caballo en su espuma que ondula el viento, imagen recogida en la poesía de todos los tiempos desde los poemas homéricos a los versos del poema a la muerte del héroe Cuchulain de la saga irlandesa que recuerda W.B.Yeats(19) (La muerte de Cuchulain, 1892: "Cuchulain stirred, Stared on the horses of the sea, and heard. The cars of battle and his own name cried; And foubt with the invulnerable tide". La nave abandonada por los griegos, que por incitación del prisionero Sinón, es hecha entrar tras los muros de Troya, incluso abriéndose paso desmontando un tramo de muralla. Debió tener un doble fondo en la bodega para ocultar a los guerreros del Odiseo de la estratagema. El virgiliano término cavernas ingentis con el que describe las entrañas del caballo corresponde en lenguaje náutico latino a la bodega de un barco (Cicerón, de or., iii, 180 y Servio), de hecho hay autores antiguos como Eurípides (Tro.,539), que ya reconocen implícitamente que el Caballo de Troya pudo ser un barco de guerra, como también opina Ruiz de Arbulo $^{(20)}$.

\footnotetext{
(19) W.B.Yeats, La muerte de Cuchulain, 1892.

(20) En una de las Aulas del Mar de la Universidad Internacional del Mar (Universidad de Murcia), dedicada a la Vida en la Mar, el Dr. J. Ruiz de Arbulo recogía algunas de estas referencias clásicas opinando en igual dirección.
} 
Este barco considerado y tratado como una ofrenda, no haría mas que mantener la tradición de la nave Argos, cuyo carpintero fue aconsejado por Atenea, en el viaje de Jasón en busca del Vellocino de Oro que culmina con su regreso a Corinto y la ofrenda naval en el santuario del Istmo (Apoll.Rhod., I,9,27). Numerosos ejemplos repiten el hecho, desde los restos de una proa con cabeza de caballo atribuida a las naves gaditanas del tipo hippoi, ligeras y veloces que describe Estrabón al narrar la historia de Eudoxos de Kyzicos a fines del II a.C. a las innumerables representaciones en la iconografía vascular sin ir mas lejos ${ }^{(21)}$. Es curioso que no sea este el único caso en que a lo largo de la historia de las navegaciones se identifican navíos perdidos precisamente por la proa (más fácilmente reconocible y resistente) como en el novelesco y real episodio de la pérdida del navío español San Telmo en aguas antárticas en 1819 y presumiblemente identificado por Fildes y Smith precisamente por los restos de su tajamar de proa, recogido luego de forma novelesca por Pío Baroja. $^{(22)}$

Las ofrendas de barcos reales en santuarios, completos o en parte, los rostra entre los que los mas famosos fueron los de Egina y las trirremes de Salamina, Delos y posteriormente los augusteos de Actium, son una continuación de la tradición naval que llega a nuestros días. (Recientemente unos aventureros buceadores uruguayos han recuperado de aguas del Río de la Plata el águila explayada con la svástica entre sus garras del acorazado de

\footnotetext{
(21) Originariamente eran consideradas naves mercantes construidas por los fenicios, Casson, op. cit., p.66, documentadas a partir de los relieves asirios del 700 a.C. en que aparecen dedicadas al transporte de troncos de madera. No debió ser infrecuente este tipo de remate precisamente por su inspiración y connotaciones con el propio caballo como animal de transporte y carga.

${ }^{(22)}$ Pío Baroja recoge en un delicioso relato corto la desafortunada historia del barco relatando la muerte de su capitán acompañado de su fiel perro que permanecerá junto a él en sus últimos momentos para perecer de frío. El mismo hecho de la referencia a la recuperación por William Smith de la madera del cepo de un ancla del San Telmo hallada en la Ensenada de la Media Luna de Isla Livingston en el archipiélago de las Shetland del Sur, para mandar hacer con ella un ataúd para su uso personal, entra de lleno en el contexto romántico del siglo XIX en el que la vecindad de la muerte constituía una imagen casi inseparable de muchas situaciones. Para mayor información sobre el Navío San Telmo ver la bibliografía de Martín-Bueno, M. al respecto como resultado de las investigaciones antárticas del Proyecto San Telmo en los años 1993 y ss.
} 
bolsillo alemán Graff Spee que adornaba su proa en la más clásica tradición naval) ${ }^{(23)}$. Debemos considerar que si se elegían los rostra como trofeo era precisamente porque solían estar decorados con formas identificables (con cabezas de jabalí los samios) o mas frecuentemente llevar en el propio espolón el nombre del barco y aún del propio almirante de la flota. Los inventarios epigráficos del santuario de Delos cuentan entre sus registros la ofrenda del navío del almirante de Antígono, una gigantesca triarmenos de tres palos, la Isthmia, con la que venció en la isla de Cos a los generales de Ptolomeo. Tal vez la misma nave que vio mas tarde Pausanias en el santuario de Delos en el s. II a.C..

La ausencia de recursos para la navegación como instrumentos para la ayuda en la observación astronómica y el poderoso compás, descubiertos luego, hizo que la aventura de la navegación fuera durante mucho tiempo una práctica bien arriesgada. La falta de información sobre lo que tenían debajo de la quilla, relieve del fondo, profundidad, corrientes, etc. hacía del arte de navegar una práctica realmente peligrosa. Por otra parte ese sentimiento de miedo-respeto ante lo desconocido de la gente de mar de todos los tiempos es proverbial, baste recordar que la gente de mar, los hombres embarcados, los que viven de ella y pasan mas de media vida sobre "suelo movedizo" casi nunca sabían nadar, ¿pura contradicción? ó pánico a lo desconocido y sobre todo a los peligros que encierra que se prefiere ignorar con un fatalismo paralizante.

\footnotetext{
(23) La recuperación se inscribe en una operación de simple salvamento marítimo rodeada de toda la publicidad posible para atraer la atención de eventuales inversores para otras operaciones de mayor calado. La controversia ha surgido inmediatamente, al tratarse de un buque significativo de aquel periodo, con una cierta repercusión en los medios de comunicación alentados interesadamente por los protagonistas de la recuperación. La inexistencia de una legislación de patrimonio ad hoc en la República Oriental de Uruguay impide una actuación administrativa de mas alcance pero ya las autoridades competentes se han pronunciado impidiendo la exportación de dicha pieza por considerarla como parte integrante del patrimonio subacuático nacional.
} 
La carencia de cartas náuticas ha sido sin duda históricamente uno de los mayores problemas ${ }^{(24)}$. Así por ejemplo hablando de los alrededores de Troya

la Eneida nos relata:

\begin{abstract}
"A la vista de Troya está la isla de Ténedos, sobrado conocida por la fama. Abundaba en riquezas mientras estuvo en pie el reino de Príamo, Hoy solo una ensenada, fondeadero traidor para las naves. Hasta allí se adelantan los dánaos y se ocultan en la playa desierta"
\end{abstract}

(Eneida, II, 13-23.)

Fondeadero traidor seguramente porque se ignoraban sus características y porque era capaz de permanecer al soslayo de miradas indiscretas ${ }^{(25)}$.

El barco homérico no fue un barco genérico, era un tipo de sobra conocido y extendido por todo el Mediterráneo al parecer, un híppos, un barco con mascarón de proa en forma de cabeza de caballo, seguramente del mismo tipo que los que fueron representados como barcos fenicios de época arcaica en los relieves asirios que adornan las placas de bronce que revestían las puertas del palacio de Salmanasar III (854-824 a.C.), en las que muestran los tributos de Tiro y Sidón mediante unos barcos simétricos decorados con caballos a proa y popa (roda y codaste). El ejemplo más preciso y

\footnotetext{
(24) En el mundo antiguo no existieron como tales pero son un antecedente los periplos tanto fenicios, griegos o cartagineses y romanos que nos relatan con mas pormenor de lo que parece los recorridos efectuados en sus navegaciones describiendo puntos de referencia importantes, asentamientos humanos, desembocaduras de ríos, etc. En estas fuentes encontramos descripciones, al menos desde el siglo VIII a.C. con datos preciosos para poder recrear las dificultades de aquellas navegaciones a la par que para identificar muchos lugares. El conocimiento de la salida al Atlántico desde fecha muy antigua (VIII a.C.) lo tenemos atestiguado en Hecateo, luego en Scylax, Hannón, Artemidoro, Pausanias, Esteban de Bizancio, Estrabón, Plinio el Viejo, etc. lo que nos permite además analizar la diferente situación de algunos puntos clave de la costa, así como sus accidentes, lugares de fondeo o arribada, etc.

(25) El problema de los fondeaderos en aquella época y en tiempos posteriores era fundamentalmente el del acceso tanto para la arribada como para la partida, así como por las ventajas que pudiera ofrecer como abrigo de los vientos e incluso de miradas enemigas. Una buena ensenada, a menudo la desembocadura de un río de curso manso (generalmente la mayoría en su curso inferior) podía ser un buen refugio pero también una ratonera. Las barras litorales en las desembocaduras constituyeron durante los tiempos de la navegación a vela lugares muy propicios para los naufragios, auténticas trampas. El conocimiento del flujo de las mareas era fundamental, así como el aterramiento progresivo de muchos estuarios y lagunas litorales de los que el Mediterráneo cuenta con un amplio repertorio de oriente a occidente.
} 
monumental es el famoso relieve de piedra del palacio de Sargón II en Khorsabad (722-705 a.C.), hoy en el Louvre, que muestra un transporte por mar de grandes troncos con ayuda de barcazas movidas a vela y remo entre ciudadelas situadas en islotes (representando a las ciudades fenicias) ${ }^{(26)}$. Las proas adornadas con cabezas de caballos y su alusión directa a la velocidad sobre las olas en boga rápida nos permiten entender rápidamente la elección del caballo como animal totémico para estos pequeños barcos, auténticos "caballos del mar", como ya se vio antes.

Algunos autores, entre ellos Guerrero ${ }^{(27)}$ han tratado sobre la tipología de los mercantes fenicios, recogiendo y analizando estos modelos: los gauloi de altamar, cargueros pesados y redondos movidos por vela cuadra y los ligeros y alargados híppoi, movidos a vela y remo, aptos para el cabotaje, la pesca, la carga y descarga en las bahías de aguas profundas. De ellos da cuenta la obra de L. Basch, magnífica pero menos citada de lo que se debiera ${ }^{(28)}$.

"Según Poseidonio, Eudoxos de Kyzicos, en tiempos del rey Evergetes II de Egipṭo (146117 a.C.) y de sus dos sucesores inmediatos, exploro por dos veces las costas del Océano Indico; a la vuelta de su segundo viaje tocó en las costas etiópicas, donde recogió una lista de palabras. Se encontró también con la proa de madera de un navío, en el que estaba tallada la figura de un caballo, y supo que eran los restos de un naufragio de cierta escuadra que partió de Occidente; con ella emprendió de nuevo su viaje de regreso... Llevó su proa al puerto comercial de Alejandría y allí supo que era de los de Gadir, y que éstos, además de los grandes navíos que armaban los comerciantes, usaban otros más pequeños, propios de las gentes pobres, a los que llamaban híppoi, por el mascarón de sus proas; con ellos pescaban a lo largo de las costas de Mauritania, hasta el río Lixos. Además, ciertos pilotos reconocieron esta proa como perteneciente a una de las naves que habiéndose alejado mucho del río Lixos, perecieron. Deduciendo de ello Eudoxos que la circunnavegación de la Libia (Africa) era posible, volvió a su patria y embarcando todos sus bienes, partió. (Estrabón II, 3,4).

La singularidad de las navegaciones antiguas, pese a los evidentes peligros que encerraba es precisamente su prolijidad, el espíritu aventurero de los

(26) Casson, cit.supra, fig. 92.

$\left({ }^{27}\right)$ Guerrero Ayuso, V.M., 1998 La navegación en el mundo antiguo. Mercantes fenicios y cartagineses. Aldaba, 30, Melilla 1998, pp. 141-192; Los mercantes fenicio-púnicos en la documentación literaria, iconográfica y arqueológica, Treballs del Museo Arqueologic d'Eivissa e Formentera, $\mathrm{n}^{\circ}$ 41, 1998, pp. 61-103; La Marina de la Cerdeña Nurágica, PYRENAE, 35, 1, 2004, pp. 117-155.

$\left.{ }^{28}\right)$ Basch, L. Le musée imaginaire de la marine antique, Atenas 1987, pp. 303-336. 
pueblos no conoce límites, ni a la imaginación, ni a la ambición y seguramente mucho menos al hambre.

Las navegaciones de muchos de ellos, griegos notoriamente estuvieron marcadas por la necesidad de buscar allende los mares el sustento que sus empobrecidas tierras que soportaban ya una presión demográfica a la que era incapaz de responder. Este es sin duda uno de los acicates de la emigración de todos los tiempos y sin duda ahora todavía en que vemos diariamente como gentes de tierra adentro, se arriesgan a poner su futuro y su vida (muchos la pierden) en manos de los elementos naturales, muchas veces inmisericordes para alcanzar el espejismo del mundo occidental atravesando por ejemplo el terrible y peligrosos Estrecho de Gibraltar a bordo de frágiles y sobrecargadas embarcaciones guiados tan solo por las luces del capital en los días bonancibles y si mas rudimentos como ayuda de la navegación que algunos de los navegantes antiguos y sin duda con el mismo temor a lo desconocido.

Las fuentes griegas resultan a este respecto diáfanas: nadie se lanzaba a realizar travesías marítimas sino fuera motivado por la pobreza, la falta de recursos agrícolas, las malas cosechas y las hambrunas resultantes. Nada nuevo bajo el sol. Ante estas expectativas como no vamos a comprender las ofrendas de barcos votivos a lo largo de todos los tiempos, desde los barcos que habían protagonizado hazañas espectaculares como en el mundo clásico a los modelos mas reducidos, verdaderas maquetas atestiguadas desde época minoica y muy abundantes todavía en nuestros santuarios costeros, testigos mudos de tantas y tantas tragedias en forma de naufragios y pérdidas humanas. El santuario de San Andrés de Teixido gallego (vai de morto qui non foi de vivo) es muy elocuente al respecto.

La necesidad de resolver el problema de ir y volver sanos y salvos, de superar una travesía marina no era cosa baladí. Las ofrendas a los dioses servían para intentar garantizar un viaje seguro. La razón última de todas estas precauciones procuraba asegurar el salvos ire/salvos venire que recogen los 
epígrafes votivos latinos, pero la decisión final estaba en manos de los dioses y había que propiciarlos adecuadamente algunas veces consistentes en el propio barco como el referido Argos (Apoll. Rhod., I,9,27) en el santuario de Corinto ya mencionado, o los referidos por Herodoto (VIII, CXXI), tras Salamina frente a Jerges

"(Los griegos) lo primero que hicieron fue entresacar del botín varias ofrendas que como primicias destinaban a los dioses, como particularmente tres galeras fenicias, una para dejarla en el Istmo, la que hasta mis días se mantenía en el mismo punto; otra para Sunion y la tercera para Eante en la misma Salamina. En segundo lugar repartiéronse el botín, enviando a Delfos las primicias de los despojos, de cuyo precio se hizo una gran estatua de doce codos que tiene en la mano un espolón de galera..." (Herodoto, VIII, CXXI).

Los secretos que conservan los fondos marinos son innumerables, no olvidemos que cuatro quintas parte de la superficie del planeta que habitamos está cubierta por mares y océanos y buena parte de la historia desarrollada sobre la superficie terrestre y sobre el agua, ha ido a parar al fondo y allí reposa hasta que poco a poco la tecnología permite que los arqueólogos alcancemos con nuestro método característico cada vez cotas mas altas de efectividad y mayores profundidades. Arqueología, Filología, Epigrafía o Numismática van facilitando una visión de esa prolongación de la historia de superficie con la información recogida para completar el panorama general.

Hoy sabemos que complicaciones gastrointestinales, diarreas, disentería, mareos, náuseas, etc., que ya no suponen otra cosa que molestias e incomodidades para la navegación actual eran obstáculos mucho mas determinantes en otros tiempos. El mismo escorbuto, ya sufrido por la gente de mar en época romana, consecuencia de la imposibilidad de conservar durante cierto tiempo los alimentos frescos, se han superado con la capacidad de generar energía para los frigoríficos embarcados y en su estadio anterior el almacenamiento de hielo. Ese simple hecho del deterioro rápido de los alimentos frescos suponía situaciones catastróficas. La limitación de la navegación mediterránea por otra parte para evitar riesgos climatológicos 
entre el 21 de noviembre y el 21 de marzo, el mare clausum, no facilitaba precisamente las cosas ya que la navegación se concentraba precisamente en los meses más cálidos. No obstante son pocas las fuentes literarias sobre aquellos problemas alimentarios a bordo, tan solo la referencia al panis nauticus mencionado por Plinio (N.H. XXII, 138), pan sin levadura, muy cocido, que se comía seco y muy duro digerible tan solo remojado en agua o caldo, antecedente de la galleta marinera de tiempos posteriores.

Aspectos relativos a la cocina a bordo, utensilios (incluidos los molinos para grano con que se preparaba la harina), conocemos gracias a yacimientos como Yassí Ada en Turquía (excavado por G. F. Bass en los años sesenta) ${ }^{(29)}$ o el posterior de Comacchio (Ferrara) con restos de una planchà en hierro para cocinar, suponemos que carne y sobre todo pescado como relatan las fuentes para tiempo bonancible y como necesidad en caso de naufragio con supervivencia (Juv. XII,60-61).

Se conoce mucho acerca de los tipos de pasajeros y equipaje para época griega y sobre todo romana, la ingente cantidad de pecios mercantes de varias épocas permite reconstruir el momento con bastante seguridad. Elementos comunes en los barcos como anzuelos, leznas, pesos de plomo, restos de redes, etc. atestiguan la actividad pesquera, junto a los restos de comida y alimentos de algunos de estos pecios, como conchas de moluscos, espinas de peces, etc.

La organización del tráfico marítimo, las rutas comerciales, los derroteros, los puertos y sus aproximaciones, la estructuración de las empresas y organizaciones de navegantes con sus sedes y delegaciones son también conocidas. Las oficinas de los navicularii en muchas ciudades del Mediterráneo eran sucursales de las centrales de la propia Roma u Ostia. Gianfrotta $^{(30)}$ cita la presencia de delegaciones de los navicularii de Arelatum

\footnotetext{
(29) Bass, G.F. Van Doornick, F.H., Yassí Ada, a Seventh-Century Byzantine Shipwreck, I, 1982.

(30) La amplísima bibliografía de Gianfrotta, P. A., debe iniciarse por Gianfrotta, P.A., y Pomey, P, L'Archeologie sous la mer, 1980, en la que se recogen muchas de estas referencias, también en Rougé, J., op. cit.
} 
en Beirut de los de Nicomedia de Bitinia tenían presencia frecuente en Rabenna, Spalato e Hispania. Por otra parte conocemos algunos datos relativos al transporte de pasajeros, a los seguros, etc. Por ejemplo la lex rbodia (2,9 y 13) dice que en el momento del embarque el pasajero adquiría solamente el derecho a una superficie mínima del puente de poco mas de un metro cuadrado, debiendo resolverse por sus propios medios el avituallamiento que debía transportar consigo para todo el viaje, calcular periodos sin viento (encalmadas), etc. Problema que no fue privativo del mundo antiguo sino que llegó en circunstancias similares hasta la edad moderna, incluso en aquellos viajes en los que con el precio del pasaje estaba comprendida la alimentación, por lo general bastante escasa. Los problemas de intimidad, higiene, salubridad e incluso directamente médicos simplemente terribles.

Ante estas expectativas no es extraño que se recurriese a toda suerte de remedios para facilitar las cosas y asegurar la travesía, ojos pintados en las naves contra el mal de ojo, amuletos, colocación de una moneda en la base del mástil principal (trasunto del óbolo a Caronte) para asegurar una buena travesía, como los ejemplos tardorrepublicanos de Albenga, Punta Scaletta, Brindisi, etc., falo de madera esculpido a bordo de la Madrague de Giens, amuletos, piedras semipreciosas especiales, como el corindón, el coral (considerado como piedra), cepos de ancla con inscripciones o relieves, astrágalos, delfines (muy queridos por Apolo), caduceos, la estrella como atributo de Hera (Juno) especialmente venerada para la navegación nocturna y antecedente de la Virgen católica como Stella Maris. Conchas asociadas a Venus nacida de la espuma de la mar. Las inscripciones de los cepos de plomo con dedicatorias completan un panorama de eterna búsqueda de la seguridad. Muchas naves con nombres de dioses, consignados en los cepos de ancla muestran la repetición de estos (como en la actualidad), Zeus, Iupiter usados tanto para naves mercantes como militares por barcos de la flota de Ravenna. Muy frecuente Venus o Afrodita, a veces asociada con Júpiter. 
Frecuente fue Soteira (salvadora), y mas escasos: Delfinio, Artemio, Ceres, Heracles, Isis, Salvia, Tiche, Vesta.

La puesta a punto de la escafandra autónoma en los años cuarenta del pasado siglo, permitió que lo que hasta entonces era un sueño casi apenas atisbado se convirtiera en poco tiempo en una realidad tangible. La definición de la nave hundida como una cápsula de tiempo atribuida a Bass ${ }^{(31)}$, dejó en ese momento de constituir una meta inalcanzable para convertirse en algo cotidiano. De los pecios se pasó a considerar las instalaciones costeras, los puertos, factorías, ciudades costeras hundidas por fenómenos como el braquisismo tan característico de la costa tirrena italiana. Del mundo antiguo y una arqueología de ánforas recuperadas por buceadores y puestas en manos de los arqueólogos a estos mismos convertidos en omniactores en un teatro de operaciones que dejaba de considerarse exótico para devenir en cotidiano.

Nacía la arqueología denominada impropiamente subacuática y con ella la definición del arqueólogo subacuático como aquel arqueólogo que necesita conocer y dominar la técnica del buceo para desplazarse hasta su lugar de trabajo, el yacimiento subacuático, esté en la mar, ríos o lagos. La aventura y el exotismo de esta especialidad quedaba reducida a simple ejercicio de la profesión con una finalidad, contribuir a completar la historia hecha hasta ese momento sobre bases documentales y evidencias materiales recogidas en superficie, lo que no es poco.

\footnotetext{
(31) Bass, G.F. History of seafaring on underwater archaeology, London, 1972,. En ésta obra sentó las bases de la arqueología subacuática moderna, si bien todos sufrimos una nueva transformación metodológica en la década de los años ochenta del pasado siglo. Martín-Bueno, M. La Arqueología Subacuática, A Distancia, Junio, UNED, Madrid 1989.
} 


\section{BIBLIOGRAFIA}

Anderson, M. (1995): Onesimos and the interpretation of Ilioupersis Iconography, JHS, 115, 1995, $130-135$.

Austin, R.G. (1959): Virgil and the wooden horse, JRS, 49, 16-25. (1980): P. Vergili Maronis, Aeneidos. Liber Secundus, Ed. and comment., $3^{\text {a }}$ ed. (1964), Clarendon Press, Oxford.

Basch, L. (1987): Le Musée imaginaire de la marine antique, Atenas.

Boardman, J. (1975 a): Athenian Black Figure Vases, Ed. Thames and Hudson, Londres. (1975 b): Athenian red figure vases. The archaic period, Ed. Thames and Hudson, Londres.

— (1975 b): Athenian red figure vases. The archaic period. Ed. Thames and Hudson, Londres.

Braccesi, L. (1994): Grecità di frontiera, Padua.

Carpenter, Th. H. (1994): Art and Myth in Ancient Greece, Londres (2 ed.).

Casson, L. (1971): Ships and seamanship in the Ancient World, Princeton.

- (1974): Travel in the Ancient World, Londres.

- (1991): The Ancient Mariners, Princeton (2 ed.).

Castagnoli, F. (1981): La leggenda di Enea nel Lazio, Enea nel Lazio, archeologia e mito, Catal. Expos. Roma, Roma, 3-5.

Desroches-Noblecourt, Ch. (1963): Vida y muerte de un faraón, Tutankhamen, ed. Herder, Milán.

Detienne, M. (1970): Le navire d'Athena, Revue de l'Histoire des Religions, 177, 9-177.

Enea nel Lazio 1981: AAVV, Enea nel Lazio, archeologia e mito, Catal. Expos. Roma, Roma.

Ervin, M. (1963): A relief pithos of Mikonos, ArchDelt, 18, 1963, 51-65.

Exvoto 1981: Exvoto marins de l'Antiquité a nos jours, Musée de la Marine, París.

Gianfrotta, P. (1997): Les marins et les passagers, Pomey, P. (dir.), La Navigation dans l'Antiquité, Aix, 102-113.

Guerrero, V.M. (1998): Los mercantes fenicio-púnicos en la documentación literaria, iconográfica y arqueológica, Rutas, navios y puertos fenicio-punicos. XI Jornadas de Arqueología feniciopunica (Eivissa 1996), Eivissa, 61-104.

Hart, M.L. (1992): Athens and Troy. The narrative Treatment of the Iliupersis in Archaic Attic VasePainting, Los Angeles, 1992.

Heilmeyer, W.D. (1988): Antikenmuseum Berlin. Die ausgestellten Werke, Berlín.

Luzon, J.M. (1988): Los hippoi gaditanos, Congreso Internacional "El Estrecho de Gibraltar" (1987), Madrid, 445-458. 
Musei Capitolini (2000): AAVV, Musei Capitolini, ed. Electa, Roma.

Pipili, M. (1997): s.v. Ilioupersis, LIMC VIII. Suppl., Zürich. Reeves, N. (1990): Todo Tutankamón, Ed. Destino, Barcelona.

Rossi, L.E. (1982): Los poemas homéricos como testimonio de la poesía oral, Bianchi Bandinelli, R. (dir.), Historia y civilización de los griegos, Barcelona (Milán 1978), 82-157.

Rougé, J. (1975): La marine dans l'Antiquité, París.

Schachermeyer, F. (1950): Poseidon und die Entstebung des griechischen Götterglaubens, Munich / Berna.

Sadurska, A. (1964): Les tables iliaques, Varsovia. (1986): s.v. Equus Troianus, LIMC, III, 813-591.

— (1986): Equus Troianus, LIMC, III, 813-591.

Sandberg, N. (1954): Euploia. Etudes epigraphiques, Acta Universitatis Gothoburgensis, VIII, Goteborg. 